\title{
Clinical empathy with cancer patients: a content analysis of oncology nurses' perception
}

This article was published in the following Dove Press journal:

Patient Preference and Adherence

\author{
Camelia Rohani' \\ Maryam Sedaghati \\ Kesbakhi \\ Jamileh Mohtashami ${ }^{3}$ \\ 'Department of Community Health \\ Nursing, School of Nursing and \\ Midwifery, Shahid Beheshti University \\ of Medical Sciences, Tehran, Iran; \\ ${ }^{2}$ Department of Nursing, Nursing \\ School, Tonekabon Branch, Islamic \\ Azad University, Tonekabon, Iran; \\ ${ }^{3}$ Department of Psychiatric Nursing, \\ School of Nursing and Midwifery, \\ Shahid Beheshti University of Medical \\ Sciences, Tehran, Iran
}

Correspondence: Maryam Sedaghati Kesbakhi

Department of Nursing, Nursing School, Tonekabon Branch, Islamic Azad University, Mazandaran Province, 4684I6II67 Tonekabon, Iran

Tel +989113379244

Fax +982188202521

Email maryamsedaghatil7@yahoo.com
Background: Empathy is one of the most important communication skills in clinical practice, specifically in the field of oncology. Empathic competences have a significant meaning for caring and therapeutic relations in nurses' responsibilities. Clinical empathy brings positive performance, thus patients' emotions are perceived and expressed more easily. Clinical empathy is contextual, interpersonal and affective, but it is also difficult to study. Awareness of oncology nurses' perception of this phenomenon might help them to plan for more effective patient-centered consultations within interventional programs. Therefore, the aim of this study was to explore the content of clinical empathy with cancer patients from the perspective of oncology nurses.

Patients and methods: In this qualitative study, 15 oncology nurses were selected by purposive sampling. A semi-structured face-to-face interview was conducted with each of the participants. After data collection, all interviews were transcribed and reviewed, and then primary codes, sub-categories and categories were extracted. The data were analyzed with the conventional content analysis method by MAXQDA 10 software.

Results: Clinical empathy showed a composite construct with five main categories, including co-presence (physical and emotional presence), metacognition (self-awareness of mental processes), perception (knowing about awareness of individuals), inherent (genetic) and didactic (instructive) nature.

Conclusion: Clinical empathy as an effective strategy can be taught through three areas of "co-presence", "metacognition" and "perception" in the context of cancer care. Thus, clinical empathy should be considered as one of the competency standards which can be taught to oncology nurses.

Keywords: clinical empathy, co-presence, metacognition, oncology nursing, perception, qualitative research

\section{Introduction}

There is still no widely accepted definition for empathy in the area of medical sciences. ${ }^{1}$ Some scholars define empathy as a cognitive ability to acquire the perspectives, perception of thoughts, intentions, affections and beliefs of others. ${ }^{2}$ Some others emphasize emotional responses to feelings and emotions of individuals. ${ }^{3}$ When analyzing the concept of empathy, it is necessary to consider the difference between similar words, like sympathy and compassion. Sympathy includes emotional connection through feelings and expression of concern or compassion. Compassion is defined as the feeling and emotion toward an individual's problems and the internal tendency to remove them. In contrast, empathy is an objective perception of a situation and emotions or values. ${ }^{4}$ In other words, empathy means the perception of emotions and concerns of individuals and attention to the world from the viewpoints of the other individuals. ${ }^{5}$ Results of 
a review study on empathy showed that there are five conceptualizations since 1990. Empathy has been disclosed as a human trait, a professional state, a communication process and as caring, also a special relationship. ${ }^{6}$ The exploration of the concept of empathy in coach-athlete communication by a qualitative study indicated that empathy includes five themes: advocacy, communication, approachability, access and competence. ${ }^{7}$

Empathy is a multidimensional construct and includes cognitive, affective, behavioral and ethical dimensions. ${ }^{8}$ The cognitive dimension involves analytical and intellectual skills for perception of individual's views. The affective dimension is the ability to share internal and emotional conditions of other individuals. The behavioral dimension reflects an empathetic relationship based on perception and communication skills, including active listening. The ethical dimension includes altruistic motivation. ${ }^{9}$ The most controversial side of empathy may be the cognitive or affective aspects. ${ }^{10}$ According to the results of a review, most researchers believed that empathy included both cognitive and affective aspects. ${ }^{1}$ Mercer and Reynolds ${ }^{8}$ defined another type of empathy as clinical empathy. This is a perception of the situation, perspectives and emotions of the patient, communication with the patient, and evaluation of performance based on the patient's perception in a helpful or therapeutic way. Clinical empathy is contextual, interpersonal, affective and it is difficult to study. ${ }^{11}$ The humanistic psychologist Carl Rogers discussed genuineness or congruence in empathy as most important in facilitating communication. ${ }^{12}$ The congruence has clearly two components, an internal component involving awareness of one's own experience and an outer component, transparency which refers to obvious communication. ${ }^{13}$

A review of nursing literature shows that some authors addressed the concept of empathy in their models or theories. ${ }^{14}$ For example, one of the concepts in the Travelbee model is the phase of empathy. In her human-to-human relationship model of nursing, she stated that nurses were able to be empathetic with patients who showed similar behavioral and ethical features with them. Peterson and Zedrad described nurse-patient communication as a mental transaction. This, together with empathy, opinion exchange and discussion are the foundations of nursing. ${ }^{14}$

Evidence indicates that the skill of clinical empathy is necessary for oncology nurses. Clinical empathy brings positive performance, thus patients' emotions are perceived and expressed more easily. ${ }^{15}$ Cancer patients are in a vulnerable situation due to changes in their quality of life and deterioration of their health, following multiple side effects of treatments. It is more challenging to communicate with these patients. ${ }^{16}$ Development of nurse-patient empathic communication in the oncology ward is essential for patients to relieve their psychological distress. ${ }^{17}$ Cancer patients are frequently hospitalized during their illness and nurses have more opportunity to build an empathetic relationship with them, to attract their trust and to support them and their families. ${ }^{18}$ Nurses are able to identify empathetic opportunities and respond to patients' needs, which can help patients to adapt to their illness. ${ }^{19}$ A review study ${ }^{20}$ showed that empathetic relationship can improve outcomes of caring and treatment in patients in two ways: first, it can lead to selfdisclosure of most signs and concerns of patients, acquiring more information, more accurate diagnosis, perception and responsibility of therapist to personal needs of the patient, thus better outcomes. Second, empathetic relationship causes a sense of being listened to, valued as an individual, understood, and accepted, leading indirectly to the improvement of patient outcomes. ${ }^{20}$ A study of 710 patients in Germany indicated that there was a significant relationship between therapists' empathy, reduced depression and promotion of patients' quality of life. ${ }^{21}$ In addition, results of a retrospective study showed that therapists' empathy was associated with higher satisfaction and lower distress in patients. ${ }^{22}$

An extensive review of international and Iranian databases, such as Cumulative Index of Nursing and Allied Health Literature (CINAHL), Web of Science, PubMed, Google Scholar, Ebsco, Iranmedex and Scientific Information Database (SID) using keywords of clinical empathy, empathy, oncology, qualitative research and quantitative research, nurse and cancer patient within 10 recent years (2007-2017) indicated that most previous studies were conducted quantitatively on physicians and medical students' empathy with patients. ${ }^{22-24}$ There were few quantitative studies about Iranian nurses' empathy with patients in the oncology ward, ${ }^{25}$ surgical ward ${ }^{26}$ and intensive care unit. ${ }^{27} \mathrm{We}$ found only two qualitative studies in nurses, ${ }^{28,29}$ but they did not explore the content of empathy. Thus, the present study was conducted with the aim of exploring qualitatively the nature of clinical empathy with cancer patients from the viewpoint of oncology nurses.

\section{Patients and methods Study design}

This qualitative study is part of a mixed method project which was conducted by a conventional content analysis method.

\section{Participants}

By purposive sampling, 15 nurses were employed from oncology wards (oncology, hematology-oncology and stem cell transplantation wards), including nine women and 
six men. Inclusion criteria were: working in oncology wards as a nurse with a minimum 6-month experience, and having at least a bachelor's degree in nursing.

\section{Data collection}

Data were collected from February 2015 to September 2016. Based on the aim of the main project and according to oncology nurses' responses to the Persian version of the Jefferson Scale of Empathy-Nursing Student version $\mathrm{R}$ (JSE-NS version R) on the normal distribution curve, ${ }^{30}$ nurses as participants were selected from seven educational hospitals affiliated to three Tehran Universities of Medical Sciences. After obtaining informed written consent from each participant, semi-structured interviews were conducted with 15 oncology nurses. During sampling, variation in age, gender, work experience, marital status, and job title was maintained in participants.

Interviews were held in a private room of selected hospitals, and lasted 17-45 minutes. They were conducted with only the interviewer and interviewee present. The content of the interviews was based on the oncology nurses' perception and their actual experiences of empathy with cancer patients. General questions were asked regarding the participants' experiences of close communication with cancer patients and definition of empathy. Participants' responses directed the process of continuing the interview. To obtain more information and more specific answers, the participants were asked to provide objective examples. Examples of the interview questions include: "What experience do you have about close communication with your cancer patients?", "What experience do you have about empathetic communication with your cancer patients?", "What's the meaning of empathy from your perspective?" All interviews were recorded by a digital voice recorder, and then transcribed. Data gathering continued until data saturation, ie, when new information did not emerge. After 12 interviews, there was no new information, but to be sure, three more interviews were performed.

\section{Ethical consideration}

This study was approved by the Research Ethics Committee of School of Nursing and Midwifery at Shahid Beheshti University of Medical Sciences in Tehran, with the ethical code of SBMUZ.REC.1394.55. The required permissions were obtained from all of the selected educational hospitals. Objectives and procedures of the study were explained to the participants. The authors noted the ethical principles of anonymity, confidentiality of information, and the right for voluntary withdrawal from the study at any stage.

\section{Data analysis}

In this qualitative study, data analysis was done using a conventional content analysis method based on five steps of Graneheim and Lundman. ${ }^{31}$ Data analysis was started immediately after the data gathering. To do content analysis, the second author (MSK) listened to the recorded interviews, transcribed them, and read them several times. After that, all transcriptions were given to the first author (CR), and she randomly checked several transcriptions. For analysis, at first, "meaning units" were found from expressions of the participants, then primary codes were extracted. To draw out the codes, the data were reviewed word by word, and related codes were written. Afterwards, similar codes were placed in one subcategory and similar subcategories formed the categories. The data were analyzed by MAXQDA 10 Software.

\section{Rigor}

In this study, four important criteria, credibility, conformability, dependability, and transferability, were assessed to obtain the study rigor. ${ }^{32}$ Regarding credibility, the researcher was continually involved with participants and research data for seven months during data collection, analysis and interpretation. Transcribed interviews and extracted codes, as well as subcategories were discussed with and confirmed by three participants and five university members (three doctoral students in nursing and two faculty members in the Nursing and Midwifery school with a doctoral degree in nursing). To obtain rich data, oncology nurses with different demographic characteristics were chosen as participants. In addition, participants with different scores of empathy based on a previous measurement by the Persian version of the JSE-NS version R were entered into the study. ${ }^{30}$ After interviewing with 15 nurses and analyzing the results, three hospitalized cancer patients were interviewed and the codes were confirmed. The authors tried to maintain conformability of the study by reporting the obtained data in detail, recording them accurately and keeping all the documents. To assess dependability of the study, the research process stages were independently checked by three qualitative researchers with doctoral degrees in nursing, as external supervisors. A comparison of these results showed similar consequences. Despite the limitation of transferability in qualitative studies, the authors attempted to explain the method section of the study in detail, including participant selection, data collection and the research process for subsequent studies. 


\section{Results}

\section{Demographic characteristics of the participants}

Participants were 15 oncology nurses (6 male and 9 female nurses) from oncology, hematology-oncology and bone marrow transplantation wards in educational hospitals affiliated to three universities of medical sciences in Tehran. They were between 24 and 50 years old. The characteristics of the participants are shown in Table 1.

\section{Content analysis results}

When analyzing and identifying the nature of clinical empathy of oncology nurses, 518 primary codes, 25 subcategories, and 5 main categories were extracted. The main categories were co-presence, metacognition, perception, inherent and didactic nature. The categories and subcategories together with an example of quotations are shown in Table 2.

\section{Category I: Co-presence}

Co-presence includes mental experience, perception and the sense of being with others. The sense of people of being with each other is a psychological phenomenon which may or may not match the real state of co-presence. This category includes 12 subcategories: access; altruism; giving information and keeping good communication; moral communication; relationship based on honesty; empathic concern; paying attention to spirituality; being open in communication; relationship based on trustworthiness; the elixir of love; compassionate attention; and approachability.

Table I Participant characteristics $(n=\mid 5)$

\begin{tabular}{lll}
\hline Variable & Classification & $\mathbf{N}(\%)$ \\
\hline Age (years) & $<30$ & $2(13.3)$ \\
& $>30$ & $13(86.6)$ \\
Gender & Male & $6(40)$ \\
Marital status & Female & $9(60)$ \\
& Single & $4(26.6)$ \\
Work experience in & Married & $1 \mathrm{II}(73.3)$ \\
nursing (years) & $<\mathrm{I}$ & $0(0)$ \\
& $\mathrm{I}-4$ & $3(20)$ \\
Work experience in & $\geq 5$ & $12(80)$ \\
oncology field (years) & $<\mathrm{I}$ & $2(13.3)$ \\
& $\mathrm{I}-4$ & $8(53.3)$ \\
Job title & $\geq 5$ & $5(33.3)$ \\
& Nurse & $13(86.6)$ \\
Empathy score based & Head Nurse & $2(13.3)$ \\
on the JSE-NS version R & $<60$ & $3(20)$ \\
(range: $20-\mid 40)$ & $60-90$ & $3(20)$ \\
\hline Abbrevation & $>90$ & $9(60)$ \\
\hline
\end{tabular}

Abbreviation: JSE-NS version R, Jefferson Scale of Empathy-Nursing Student version $\mathrm{R}$.

\section{Category 2: Metacognition}

Metacognition is a self-awareness of mental processes, with self-control and perception of circumstances in a creative way. The category includes six subcategories: self-control; self-awareness; recognition of the situation; flexibility; emotional reflection; and aesthetic feeling.

\section{Category 3: Perception}

Perception can be defined as knowing about awareness of individuals. The category includes three subcategories: seeing from the patient's perspective; seeing from the family of the patient's perspective; and emotional connection.

\section{Category 4: Inherent nature}

The inherent nature of clinical empathy indicates its genetic constructs. This category includes two subcategories: trait; and automatic response.

\section{Category 5: Didactic nature}

The didactic nature of clinical empathy indicates its instructive construct. The category includes two subcategories: training; and role model.

\section{Discussion}

Cancer patients are mostly in distressing situations and need emotional support. However, distressed patients don't always disclose their issues, ${ }^{33}$ and sometimes nurses are not aware of what they should do for clinical empathy with their patients. Exploring the nature of clinical empathy might help to remove some of these barriers in the future. Therefore, this descriptive qualitative study aimed to explore the content of clinical empathy with cancer patients from the perspective of oncology nurses. Results showed that clinical empathy has a composite nature in the context of cancer care. Five main categories in this study were "co-presence", "metacognition", "perception", "inherent nature" and "didactic nature".

The first main category, "co-presence", means the physical and emotional presence ${ }^{34}$ of oncology nurses with their cancer patients. Co-presence includes availability, attention, affection and mutual behavior. ${ }^{35}$ Results of a study in Sweden showed that when the patient was in need, the presence of a nurse caused physical contact, a sense of warmness and closeness to the patient. ${ }^{36}$ Furthermore, Godkin et al explained that nursing presence is synonymous with caring and includes communication, comfort, respect and informing to the patient. ${ }^{34}$ Similarly, we also found the subcategory of "giving information and keep good communication" with the patient in our study. 
Table 2 Categories, subcategories and examples of participant quotations

\begin{tabular}{lll}
\hline Category & Subcategory & Example \\
\hline Co-presence & Access & $\begin{array}{l}\text { "A patient really needs mental attention. We should not neglect them. We have to listen to them. When } \\
\text { they encounter a problem, it should be handled as quickly as possible" [N, I2]. } \\
\text { "I believe that humans should help each other, especially when that person belongs to the lower class, } \\
\text { even in the case that the person is in torment because he/she cannot speak Persian. In this case, I will go } \\
\text { to him/her and help him/her to understand what he/she wants and what he/she does not want" [N, I]. } \\
\text { "Altruism }\end{array}$ \\
$\begin{array}{l}\text { Giving information } \\
\text { and keep a good }\end{array}$ & $\begin{array}{l}\text { the disease and its progress" [N, 4]. } \\
\text { the }\end{array}$
\end{tabular}

communication

Moral

communication

Relationship based

on honesty

Empathic concern

Paying attention to spirituality

Being open in communication

Relationship based on trustworthiness

Elixir of love

Compassionate attention

Approachability

Metacognition Self-control

Self-awareness

Recognition of the situation
"Generally, I am an ethical person, I'm used to saying hello to everyone and enthusiastically say good morning when I arrive at work" [N, I].

"When we talk about the truth, we should talk explicitly and with our heart, Patients sometimes love us more than psychologists. For example, a psychologist goes to the patient and speaks to them and then we go to the patient and talk to him/her and he/she says that I like you more than that gentleman who has a professor beard. The psychologist came to me and asked me some questions, and I did not finally understand what she said. Psychologists are scientifically successful and we are successful in terms of emotional feedback. In short, you see that we are better in the emotional encounter, and we show better empathy to the patient than a psychologist" [N, 13].

"We should pay attention to patient's states. For example: the patient comes to you and he is afraid, but he tells you he is not afraid. But he presses his hands constantly. He chews his lips and shakes his legs and is terribly terrified. But when we ask him if he is afraid or not? He says no, l'm not. Here, as a nurse, you tell the patient that l've noticed your fears and concerns and I am here to help you" [N, I3].

"If you really like the patient, it is possible for you to help him physically. But also you can help him spiritually. You can do a lot for him, things that you do not do for other patients. Sometimes we talk to a patient for an hour to calm him down. And give him hope for life" [N, 8].

"During IV procedure, you can talk to the patient, or just joke with him, or you can ask him a few questions, for example: How are you today? Or, the color of this dress looks good on you. Or, how are your kids? If you can communicate with them, then patients will forget their problems and they will tell you that they are happy" [N, 6].

"I try to make a friendly relationship with the patient and his/her companion. Because they may be hiding some things or not saying some things because of the fears that they have. I want them to be relaxed and to tell me everything, even those things that they could not tell to the physician. Therefore, such a relationship can help them to recover from their disease" [N, 7].

"This is my experience when I took the patient's hand in my hand; this caused him to be calm. It was so impressive to me that it seemed like an elixir of love. Yes, it was as if the elixir of love had been injected into the patient" [N, I].

"One of my patients was seventeen years old and had a fever. I had a cervical disc and I was in a very bad state. The person I was responsible for was very oppressive and I paid a lot of attention to him. Morally I could not leave the patient. You know that now the nurses do not do the footbath, but the relatives of the patient do this. But I can remember the night that I footbathed the patient all night long. It was the air of the twilight. The voice of Azan was raised. And I still had to footbath the patient" [N, I].

"For example in the oncology ward of the hospital, leukemia patients are the same age as you are and some of them have a close relationship with you. This means that they come 7 or 8 times for chemotherapy. Then you realize that the patient has entered shock or expiration phase. I can recall three cases like this, who came to our house with their families several times and we went to their house for the intravenous cannulation (IV) procedure and that meant we had a very close relationship with each other" [N, I0]. "It is obvious that this kind of patient is very nervous and they may yell at us. We must control ourselves. It is necessary that we help the patient to be calm. If I behave like the patient, his/her behavior will be worse because they have nothing to lose" [N, 9].

"Sometimes I feel that we have to solve our own problems that we are aware of them. There are some problems that only the person himself/herself knows. A human being can hide many things from others. Things that only he/she himself/herself knows about them. If we really believe that we have a problem, then we can talk with a counselor and treat ourselves. So at first, we should treat ourselves and then we can help to the patient" [N, 7].

"I worked at night shift in the oncology ward and I was busy with work. But I recognized that I should stay beside the patient's bed for 2 or 3 minutes and talk to him/her to make him/her calm. Otherwise, I knew that if I ignore the patient's problem, this, in turn, can cause problems that later I had to spend many hours to solve them and this, in turn, can cause a delay in other works. If at that time I did not have an emergency work, or if I could do that work half an hour later, I would do it, because it really was useful" [N, I]. 
Table 2 (Continued)

\begin{tabular}{|c|c|c|}
\hline Category & Subcategory & Example \\
\hline & Flexibility & $\begin{array}{l}\text { "Sometimes we do something that is favorable for the patient. For example, the patient may say that I do } \\
\text { not want this or that thing, or he/she may ask that if it is possible to do that thing at another time? Or } \\
\text { they may say: Is it possible for me to finish my lunch or dinner? In such cases, I say no problem. Then I'm } \\
\text { leaving and I'll be back for I0 minutes and then do IV procedures. I communicate with them in this way. } \\
\text { It's all about empathy that you take care of or protect the patient" [N, 9]. }\end{array}$ \\
\hline & $\begin{array}{l}\text { Emotional } \\
\text { reflection }\end{array}$ & $\begin{array}{l}\text { "Some of my colleagues say: It's normal for us to see this situation in these patients. So at the time of } \\
\text { work, we no longer see that nurses are frowning or there is no reaction in their face. But l'm not like } \\
\text { that, for example, I woke up at } 5 \text { am and took the patient's medication for him and in that time I saw that } \\
\text { this patient's mother was caressing and kissing him, and in that time tears flowed from my eyes" [N, I]. }\end{array}$ \\
\hline & Aesthetic feeling & $\begin{array}{l}\text { "In many cases, I write a poem for the patients, and the reason for writing this poem is that I want to } \\
\text { give them positive energy. One of my patients told me that, when I read this poem, I believe in this } \\
\text { poem and this belief is very effective in my well-being. Sometimes I read impromptu poetry for them and } \\
\text { maybe later I forget that poem, but I'm used to writing special poems for every special patient" [N, 7]. }\end{array}$ \\
\hline \multirow[t]{3}{*}{ Perception } & $\begin{array}{l}\text { Seeing from } \\
\text { the patient's } \\
\text { perspective }\end{array}$ & $\begin{array}{l}\text { "A nurse should stand in the patient shoe and think in such a way that this patient is like his/her brother } \\
\text { or sister. A nurse should pay attention to the patient requests and feel the patient pain as if he/she } \\
\text { himself/herself were in pain. An oncology nurse should sympathize with the patients and if his/her patient } \\
\text { is at pain, the nurse should feel the pain and if the patient vomits or feels nausea. The nurse should feel } \\
\text { this pain and suffering and empathize with the patients" [N, 5]. }\end{array}$ \\
\hline & $\begin{array}{l}\text { Seeing from } \\
\text { the family of } \\
\text { the patient's } \\
\text { perspective }\end{array}$ & $\begin{array}{l}\text { "Like the patient family that feels mourning, for many times I myself stand in patient's family shoe and } \\
\text { most often after the patient's death we let their families spend 20-30 minutes with the deceased body to } \\
\text { say good-by to him/her. As a nurse, I have experienced the sense of losing and mourning for most of the } \\
\text { patients that I have lost" [N, I5]. }\end{array}$ \\
\hline & $\begin{array}{l}\text { Emotional } \\
\text { connection }\end{array}$ & $\begin{array}{l}\text { "For example, if a person has a high level of understanding, the nurse and patient can connect with each } \\
\text { other and in fact, this is empathy" [N, 4]. }\end{array}$ \\
\hline \multirow[t]{2}{*}{$\begin{array}{l}\text { Inherent } \\
\text { nature }\end{array}$} & Trait & $\begin{array}{l}\text { "Human beings with any level of self-sacrifice that they have, at first think of their own interests, but you } \\
\text { can find some exceptions in special nurses that they first think about their patients and if their children } \\
\text { call them, or when they themselves are hungry or thirsty, they privilege the patient over himself/herself } \\
\text { and for example, he/she tells to his/her children: ask your uncle to do this for you, I cannot do anything } \\
\text { for you now. So you can find such exceptions in nurses and some nurses are devoted" [N, I3]. }\end{array}$ \\
\hline & $\begin{array}{l}\text { Automatic } \\
\text { response }\end{array}$ & $\begin{array}{l}\text { "I think that some individuals can empathize with others automatically. Such empathy takes place in the } \\
\text { nursing of the patient, especially in cancer patients, because these patients can stimulate such a sense in } \\
\text { us more than others" [N, 3]. }\end{array}$ \\
\hline \multirow[t]{2}{*}{$\begin{array}{l}\text { Didactic } \\
\text { nature }\end{array}$} & Training & $\begin{array}{l}\text { "Learning is effective in the sense of empathy that a nurse may have. Some people are kinder than others } \\
\text { and this is due to the fact that they have learned empathy in their family environment" [N, I5]. }\end{array}$ \\
\hline & Role model & $\begin{array}{l}\text { "For example, a child may express his/her feelings easily, and the other child, on the contrary, may } \\
\text { be forbidden by his/her parents to express his/her feelings. It is possible that the child grows up in a } \\
\text { family in which the mother is affectionate. As a result, various factors contribute to the formation of an } \\
\text { empathic relationship" [N, 3]. }\end{array}$ \\
\hline
\end{tabular}

Abbreviation: $\mathrm{N}$, nurse.

In the present study the subcategories of "altruism" and "moral communication" in the co-presence area emphasize ethical empathy at the clinical level. Ethical empathy is one of the dimensions of empathy ${ }^{8}$ and the authors believe that it includes altruistic motivation. ${ }^{9}$ Moreover, "trust" appeared as an important factor in the relationship between the oncology nurse and the patient in subcategory "relationship based on trustworthiness" in our study. Indicators that can improve "trust" in this relationship are as follows: honesty, trustworthiness, confidentiality, providing the best care, having a holistic view of the patient and their situation, perceiving the patient's problems, accepting their culture and beliefs without judgment and presenting a high-quality consultation. ${ }^{37}$
The role of patients' spiritual concerns in their health care conditions has been revealed in the past two decades. ${ }^{38}$ Paying attention to spirituality raised among subcategories of co-presence in our results. It can help cancer patients to keep their hope after diagnosis and during the process of treatment. ${ }^{39}$ Paying attention to spirituality includes compassion, presence, listening and encouragement of the patient's hope. ${ }^{40}$ In a qualitative study on spiritual needs of cancer patients in Iran, seeking for tranquility appeared as one of the main categories, with subcategories of hope, relationship with God and prayer. ${ }^{41}$

"Being open in communication", "the elixir of love", and "approachability" were extracted from the sense of 
co-presence of oncology nurses. In a qualitative research on "what is the meaning of empathy for doctors?" having an open communication with the patient was a main component. Also, respecting patients' emotions and thoughts was reported as an attitudinal-communication skill. ${ }^{42}$ Most physicians described that empathy appeared to be verbal and non-verbal communication skills. They described affection in facial expression, keeping eye contact and leaning forward or toward a patient to emphasize listening, as non-verbal communications. Others referred to the importance of physical contact, such as putting a hand on the shoulder of the patient, hugging, and giving tissues to the patient when she/he is crying. ${ }^{42}$ Consistent with this study, in the present research oncology nurses stated that they take the patient's hand to transfer their empathy to the patient. Oncology nurses in our study called it "elixir of love". Sitting beside the patient, taking his/her hand and caressing his/her face and hands show caring characteristics of the caregiver. ${ }^{36}$ "Compassionate attention" in our study was also similar to care and compassion, which appeared as subcategories of "genuine empathy" in a research on optimization of empathy in patient-centered care. ${ }^{43}$

When exploring the nature of clinical empathy in the present study, the second main category was extracted as "metacognition". Metacognition is an essential factor for the development of clinical empathy. ${ }^{44}$ Being aware of many variations in human cognition causes the individual's mind to move from self-orientation to other-orientation, leading to acceptance and deep empathy. ${ }^{44}$ Evidence shows that "metacognition" emerged as one of the factors following exploratory factor analysis of the concept of empathy in quantitative studies, ${ }^{25,45}$ but the components were not clear. The authors of those studies defined "metacognition" as an active effort for thinking the same as the patient. ${ }^{45}$ Results of our current research presented a better perception of "metacognition", as part of the nature of clinical empathy. It included a personal ability to control special emotions and tendencies and behavior in special and difficult situations. Also, it contained self-awareness, identification of situations, being flexible when caring for the patient, showing emotional reflection to affective states of patients and a sense of aesthetics. The results of a study at Surrey University, UK on 24 right-handed participants who were screened for using transcranial magnetic stimulation showed that the ability to control themselves and others assisted empathy as well as other social interactions. ${ }^{46}$ Additionally, "internal awareness" is the simplest aspect of "genuine empathy". ${ }^{47}$ "Internal awareness" means the awareness of self-emotions and reactions. This awareness helps therapists make reliable explicit interpersonal communication with the patient. Such "internal awareness" and contact naturally originate from being truly present with the patient. Awareness of internal experiences is effective, especially those that are created by moment interactions with patients. ${ }^{47}$ Results of a research on empathy in Iran showed that most nurses predicted patients' needs, and nurses provided some opportunities for tears and expression of emotions by the patient. ${ }^{26}$ We found the subcategory of "emotional reflection" in the area of "metacognition". Bayne et $\mathrm{al}^{43}$ discussed the concept of "accurate reflection" in medical students at Medical School of Eastern Virginia. ${ }^{43}$ "Accurate reflection" means to perceive a patient at a genuine empathic level. Health care providers should be able to convey their empathic perceptions to the patient through showing accurate emotional expressions and statements. ${ }^{43}$ Results of our study indicated the subcategories of "recognition of situation" and "flexibility" as part of the nature of clinical empathy in the metacognitive area. These results are consistent with a finding which showed that nurses changed their work schedule to find an opportunity to talk with a depressed patient. ${ }^{26} \mathrm{~A}$ striking result of our study is the "feeling of aesthetics" as a part of the nature of clinical empathy in subcategories of "metacognition". Davis described this sense as "fantasy" which was manifested as a subscale in the Interpersonal Reactivity Index for measuring empathy. ${ }^{48}$ Davis found this creative sense led to better empathy with others. ${ }^{48}$ Carper also describes the concept of "nursing aesthetics" and defines it as appreciation of and empathy toward patients' experiences and the capacity for designing comprehensive creative care. ${ }^{49}$

During exploration of the nature of clinical empathy in the present study, the third main category was extracted as "perception". This means knowing about the awareness of individuals. ${ }^{50}$ Results of the current study showed that the category of "perception" included seeing from the family of the patient's perspective, and "emotional connection". In the literature it has been argued that "perception" should be considered a result of perspective taking, one of the aspects of cognitive empathy. ${ }^{51}$ In a phenomenological study, it was found that seeing from the patient's perspective created a better perception for nurses. ${ }^{52}$ In a qualitative content analysis study with physicians in Netherlands, most physicians stated that emotional connection with the patient is necessary for empathetic communication. ${ }^{42}$

Thus in our study, three important categories of "copresence", "metacognition" and "perception" appeared to be an important part of the nature of clinical empathy of oncology 
nurses with cancer patients. The concept of "congruence" was proposed by Rogers, an American psychologist. ${ }^{47}$ It seems that this concept can cover these three main categories directly and indirectly. Congruence is a holistic concept. It refers to a complex phenomenon that is set in a connection with attitudes, beliefs and intentions. ${ }^{47}$ Being congruent, means a process of awareness of own internal experiences and a willingness to have explicit communication, openness and honesty in the moment..$^{53}$ Therapeutic presence can be a precondition to congruence. ${ }^{47}$ Our results did not show a clear boundary between different kinds of empathy, as opposed to quantitative studies (cognitive, affective, ethical and behavioral empathy). ${ }^{54,55}$ Thus, the nature of clinical empathy in the context of our study showed an integration between different types of empathy, with a predominance of cognitive and affective empathy. The effects of the cognitive element are seen more frequently in the categories of "metacognition", "perception" and "didactic nature". Because of a broad interaction between cognitive and affective empathy, some authors have rejected separation of these two concepts. ${ }^{1}$ A new perspective that the authors argued about, is that, during the time that affective empathy is automatically drew out, manipulation of the cognitive component can regulate affective component. ${ }^{1}$ Another perspective suggested that the affective component is the content of empathy, whereas the cognitive component is the process of making up this content. ${ }^{1}$

In the rest of the content analysis of clinical empathy, the "inherent" and "didactic nature" of empathy appeared as fourth and fifth categories. "Inherent empathy" means genetic empathy which is transferred from one generation to another..$^{56}$ The tendency toward empathy is a stable characteristic of the personality. ${ }^{57}$ Researchers studied the responses of above 800 monozygotic and dizygotic twins in terms of empathy and they concluded that genetic factors had a role in empathic attention and personal distress as components of empathy. ${ }^{58}$ However, empathy can also be an automatic reaction. ${ }^{1}$ Neuroscientific studies showed that empathy is automatically raised up perception of an emotional issue. ${ }^{1}$ Furthermore, some individuals have more tendency to empathy than others and either low or high empathy can be a personality trait of individuals. ${ }^{59}$ The evidence suggests that empathy is a result of the interaction between state and trait. Therefore, the role of situational factors is not negligible in this area. ${ }^{1}$ Another point is that the didactic nature of clinical empathy showed that it can be controlled, ${ }^{5}$ modified, and strengthened by training. ${ }^{60}$ Evidence shows that among various kinds of empathy, cognitive empathy can be trained successfully in the medical sciences area through role play, empirical education and education about human communications. ${ }^{61}$

The clarification of the nature of clinical empathy can assist more effective future studies in cancer patients with longitudinal or interventional designs. Future research is suggested by focusing on these concepts in the framework of a model. It is necessary that this concept is added to the curriculum of education in nursing schools and in-service education programs in hospitals.

In summary, the nature of clinical empathy of oncology nurses with cancer patients, in the context of cancer care, includes five categories of "co-presence" (physical and emotional presence), "metacognition" (self-awareness of mental processes), "perception" (knowing about awareness of individuals), "inherent" (genetic) and "didactic" (instructive). Clinical empathy is a skill which can be taught. Thus, it should be considered as one of the competency standards for oncology nurses. Clinical empathy in therapeutic communication with cancer patients can be taught through three areas of "co-presence", "metacognition" and "perception" in the context of cancer care. The focus should be on education in nursing schools and hospitals, regular assessment of clinical empathy by valid tools, applying feedback techniques, describing and sharing actual experiences of oncology nurses with their colleagues. Introducing role models is also advisable in nursing schools and hospitals.

The strength of this study is the selection of participants with maximum variety in terms of demographic characteristics, and empathy scores from a primarily quantitative study. ${ }^{30}$ However, all those selected oncology nurses were eligible to be interviewed, some of them did not agree, and this could affect the study results.

\section{Conclusion}

The complex nature of clinical empathy of oncology nurses with cancer patients was manifested in five categories of "co-presence", "metacognition", "perception", "inherent" and "didactic" nature. Clinical empathy as an effective strategy in therapeutic communication can be taught in the context of cancer care through three areas of "co-presence", "metacognition" and "perception". Clinical empathy should be embedded as one of the competency standards for oncology nurses. Therefore, to develop empathetic communication in oncology nurses, the focus should be on education, regular assessment, applying feedback techniques and describing and sharing actual experiences of oncology nurses with 
their colleagues. Introducing role models is also advisable in nursing schools and hospitals.

\section{Acknowledgments}

This study is part of the Doctoral Thesis of MSK, which was directly supervised by CR. This study was partially financed by the School of Nursing and Midwifery of Shahid Beheshti University of Medical Sciences. We would like to thank all oncology nurses who participated in this study.

\section{Author contributions}

$\mathrm{CR}$ and MSK planned and designed the study. The study was supervised by CR, and MSK was the leading author for drafting of the article and responsible for identifying relevant references. JM contributed to labeling of categories and subcategories. All authors were in close collaboration and responsible for critical revisions of the manuscript. All authors contributed toward data analysis, drafting and revising the paper and agree to be accountable for all aspects of the work. All authors read and approved the final manuscript.

\section{Disclosure}

The authors report no conflicts of interest in this work.

\section{References}

1. Cuff B, Brown SJ, Taylor L, Howat D. Empathy: a review of the concept. Emotion Rev. 2016;8(2):144-153.

2. Call J, Tomasello M. Does the chimpanzee have a theory of mind? 30 years later. Trends Cogn Sci. 2008;12(5):187-192.

3. Eisenberg N, D Eggum N, Di Giunta L. Empathy-related responding: associations with prosocial behavior, aggression, and intergroup relations. Soc Issues Policy Rev. 2010;4(1):143-180.

4. Clark AJ. Empathy and sympathy: Therapeutic distinctions in counseling. $J$ Ment Health Couns. 2010;32:95-101.

5. Hojat M. Empathy in patient care: Antecedents, development, measurement, and outcomes. Philadelphia: Springer Science \& Business Media; 2007.

6. Zeighami R, Rafiei F, Parvizi S. Concept analysis of empathy in nursing. $J$ Qual Res Health Sci. 2012;1(1):27-33.

7. David S, Larson M. Athletes' perception of athletic trainer empathy: how important is it? J Sport Rehabil. 2018;27:8-15.

8. Mercer S, Reynolds W. Empathy and quality of care. Brit J Gen Pract. 2002;52:S9-S13.

9. Ouzouni C, Nakakis K. An exploratory study of student nurses' empathy. Health Sci J. 2012;6(3):534-552.

10. Blair R. Responding to the emotions of others: Dissociating forms of empathy through the study of typical and psychiatric populations. Conscious Cogn. 2005;14:698-718.

11. Preston SD, de Waal FB. Empathy: its ultimate and proximate bases. Behav Brain Sci. 2002;25(1):1-68.

12. Kolden G, Klein M, Wang C, Austin S. Congruence/genuineness. Psychotherapy. 2011;48(1):65-71.

13. Frankel M, Johnson M, Polak R. Congruence: the social contract between a client and therapist. PCEP. 2016;15(2):156-174.

14. Alligood MR. Nursing Theorists and Their Work. 8th ed. St Louis: Elsevier Mosby; 2014.
15. Buyuk E, Rizalar S, Güdek E, Güney Z. Evaluation of empathetic skills of nurses working in oncology units in Samsun, Turkey. Int J Caring Sci. 2015;8(1):131-139.

16. Banerjee SC, Manna R, Coyle N, et al. Oncology nurses' communication challenges with patients and families: A qualitative study. Nurse Educ Pract. 2016;16(1):193-201.

17. Taleghani F, Ashouri E, Saburi M. Empathy, burnout, demographic variables and their relationships in oncology nurses. Iran J Nurs Midwifery Res. 2017;22(1):41-45.

18. Watts R, Botti M, Hunter M. Nurses' perspectives on the care provided to cancer patients. Cancer Nurs. 2010;33(2):E1-E8.

19. Kelley KJ, Kelley MF. Teaching empathy and other compassion-based communication skills. J Nurs Prof Dev. 2013;29(6):321-324.

20. Derksen F, Bensing J, Lagro-Janssen A. Effectiveness of empathy in general practice: a systematic review. Brit J Gen Pract. 2013;63(606): e76-e84.

21. Neumann M, Wirtz M, Bollschweiler E, et al. Determinants and patient-reported long-term outcomes of physician empathy in oncology: A structural equation modeling approach. Patient Educ Couns. 2007; 69(1-3):63-75.

22. Lelorain S, Brédart A, Dolbeault S, Sultan S. A systematic review of the associations between empathy measures and patient outcomes in cancer care. Psychooncology. 2012;21(12):1255-1264.

23. Hojat M, LaNoue M. Exploration and confirmation of the latent variable structure of the Jefferson scale of empathy. Int J Med Educ. 2014; 5:73-81.

24. Riess H, Kelley J, Bailey R, Dunn E, Phillips M. Empathy training for resident physicians: a randomized controlled trial of a neuroscienceinformed curriculum. J Gen Int Med. 2012;27(10):1280-1286.

25. Sedaghati M, Rohani C, Mohtashami J, Nasiri M. Validity and reliability of the Jefferson Scale of Empathy-Nursing Student Version R in a sample of Iranian oncology nurses. Nurs Midwifery Stud. 2017;6(2): e39505.

26. Parvan K, Ebrahimi H, Zamanzadeh V, Seyedrasooly A, Dadkhah D, Jabarzadeh F. Empathy from the nurses' viewpoint in teaching hospitals of Tabriz University of Medical Sciences, Iran. J Caring Sci. 2014;3(1):29-36.

27. Moghaddasian S, Lak Dizaji S, Mahmoudi M. Nurses empathy and family needs in the intensive care units. J Caring Sci. 2013;2(3):197-201.

28. Tuna R, Baykal U. A qualitative study on emotional labor behavior of oncology nurses and its effects. Int J Caring Sci. 2017;10(2): 929-936.

29. Banerjeea SC, Mannaa R, Coylea N, et al. Oncology nurses' communication challenges with patients and families: A qualitative study. Nurse Educ Pract. 2016;16(1):193-201.

30. Sedaghati M, Rohani C, Mohtashami J, Nasiri M. Empathy from the perspective of oncology nurses. J Compassionate Health Care. 2017; 4(7):1-10.

31. Graneheim U, Lundman B. Qualitative content analysis in nursing research: concepts, procedures and measures to achieve trustworthiness. Nurs Educ Today. 2004;24:105-112.

32. Anney VN. Ensuring the quality of the findings of qualitative research: looking at trustworthiness criteria. J Emerg Trends Educ Res Policy Stud. 2014;5(2):272-281.

33. Pehrson C, Banerjee SC, Manna R, et al. Responding empathically to patients: Development, implementation, and evaluation of a communication skills training module for oncology nurses. Patient Educ Couns. 2016;99(4):610-616.

34. Godkin J, Godkin L, Austin P. Nursing presence, patient satisfaction, and the bottom line. J Hosp Mark Public Relations. 2002;14(1):15-33.

35. Zhao S. Toward a taxonomy of copresence. Presence. 2013;12(5): 445-455.

36. Snellman I, Gustafsson C, Gustafsson L. Patients' and caregivers' attributes in a meaningful care encounter: similarities and notable differences. ISRN Nurs. 2012;2012(320145):1-9.

37. Cartter MA. Trust, power, and vulnerability: a discourse on helping in nursing. Nurs Clin North Am. 2009;44(4):393-405. 
38. Williams J, Meltzer D, Arora V, Chung G, Curlin F. Attention to inpatients' religious and spiritual concerns: predictors and association with patient satisfaction. J Gen Intern Med. 2011;26(11):1265-1271.

39. Conway J. Integrating spiritual care as part of comprehensive cancer treatment. 2010. Available from: http://media.oncologynurseadvisor. com/documents/20/ona_spirirtualcare1110_4813.pdf. Accessed June 3, 2017.

40. Astrow A, Alan B. Approaching the Spiritual and Religious Concerns of the Patient with Cancer: Creating an Environment for Dialogue Regarding Spiritual Concerns. Alexandria, VA: American Society of Clinical Oncology; 2009.

41. Hatamipour K, Rassouli M, Yaghmaie F, Zendedel K, Alavi Majd H. Spiritual needs of cancer patients: a qualitative study. Indian J Palliat Care. 2015;21(1):61-67.

42. Derksen F, Bensingb J, Kuipera S, Meerendonka M, Lagro-Janssena A. Empathy: what does it mean for GPs? A qualitative study. Fam Pract. 2015;32(1):94-100.

43. Bayne H, Neukrug E, Hays D, Britton B. A comprehensive model for optimizing empathy in person-centered care. Patient Educ Couns. 2013;93(2):209-215.

44. Eichbaum Q. Thinking about thinking and emotion: the metacognitive approach to the medical humanities that integrates the humanities with the basic and clinical sciences. Perm J. 2014;18(4):64-75.

45. Stansfield RB, Schwartz A, O'Brien CL, Dekhtyar M, Dunham L, Quirk M. Development of a metacognitive effort construct of empathy during clinical training: a longitudinal study of the factor structure of the Jefferson Scale of Empathy. Adv Health Sci Educ Theory Pract. 2016;21(1):5-17.

46. De Guzman M, Bird G, Banissy M, Catmur CPTB. Self-other control processes in social cognition: from imitation to empathy. Philos Trans $R$ Soc Lond B Biol Sci. 2016;371:1-9.

47. Greenberg L, Geller SM. Congruence and therapeutic presence. In: Wyatt G, editor. Rogers Therapeutic Conditions: Evolution, Theory and Practice. Vol 1. Congruence 1, Ross-on-Wye: PCCS Books; 2001: 131-149.

48. Davis MH. A multidimensional approach to individual differences in empathy. J Pers Soc Psychol. 1980;10(85).
49. Carper B. Fundamental patterns of knowing in nursing. ANS Adv Nurs Sci. 1978;1(1):13-23.

50. Håkansson J. Exploring the phenomenon of empathy. Sweden: Stockholm University, Department of Psychology; 2003.

51. Díaz-Galván KX, Ostrosky-Shejet F, Romero-Rebollar C. Cognitive and affective empathy: The role in violent behavior and psychopathy. Rev Med Hosp Gen Méx. 2015;78(1):27-35.

52. Tahmasebi S, Ashktorab T, Ebadi A, Alavi-Majd H. Professional socialization in clinical nurses- A phenomenological study. J Clin Nurs Midwifery. 2013;2(3):39-52.

53. Rogers CR. The necessary and sufficient conditions of therapeutic personality change. Psychotherapy (Chic). 2007;44(3):240-248.

54. Chen P, Wang G, Ma R, et al. Multidimensional assessment of empathic abilities in patients with insular glioma. Cogn Affect Behav Neurosci. 2016;16:962-975.

55. Grove R, Baillie A, Allison C, Baron-Cohen S, Hoekstra RA. The latent structure of cognitive and emotional empathy in individuals with autism, first-degree relatives and typical individuals. Molecular Autism. 2014;5:42.

56. Broederlow C. Understanding the common traits of an empath. Available from: https://www.thoughtco.com/traits-of-empaths-1724671. Accessed February 16, 2017.

57. Kim-Pong T. Dispositional empathy with nature. J Environ Psychol. 2013;35(2013):92-104.

58. Davis M, Luce C, Kraus J. The heritability of characteristics associated with disposititional empathy. J Pers. 1994;62(3):369-391.

59. Baron-Cohen S. Zero Degrees of Empathy. A New Theory of Human Cruelty and Kindness. London: Allen Lane; 2011.

60. Kelm Z, Womer J, K Walter J, Feudtner C. Interventions to cultivate physician empathy: a systematic review. BMC Med Educ. 2014; $14: 219$.

61. Batt-Rawden S, Chisolm M, Anton B, Flickinger T. Teaching empathy to medical students: an updated, systematic review. Acad Med. 2013; 88(8):1171-1177.
Patient Preference and Adherence

\section{Publish your work in this journal}

Patient Preference and Adherence is an international, peer-reviewed, open access journal that focuses on the growing importance of patient preference and adherence throughout the therapeutic continuum. Patient satisfaction, acceptability, quality of life, compliance, persistence and their role in developing new therapeutic modalities and compounds to optimize

\section{Dovepress}

clinical outcomes for existing disease states are major areas of interest for the journal. This journal has been accepted for indexing on PubMed Central. The manuscript management system is completely online and includes a very quick and fair peer-review system, which is all easy to use. Visit http://www. dovepress.com/testimonials.php to read real quotes from published authors. 